\section{Controlled trial of physiotherapy and occupational therapy for Parkinson's disease}

Physiotherapy is used routinely in Parkinson's disease, but there are no properly controlled trials to support its use. We describe such a trial.

\section{Patients, methods, and results}

Twenty-four patients with Parkinson's disease attending the neurological clinic were included in a controlled cross-over trial of physiotherapy and occupational therapy. Medication was stable in all cases, and no patient had received physiotherapy or occupational therapy before.

Speech, gait, posture and balance, tremor in the worst arm, and rigidity in the worst arm were assessed and graded as normal (0) to severely disabled (4); and the following specified activities were timed: rising from a seat, walking $6 \mathrm{~m}$, turning round, walking back to the chair, and sitting down; number of times the patient could open and close his fist fully in 10 seconds (worst hand); time taken to insert a set of pegs into a peg board; and time taken to insert a sheet of cardboard into an envelope. After initial assessment the patients received either active or inactive treatment. They were then reassessed, and after a three-month gap crossed over to receive the alternative treatment. For each treatment the patients attended hospital eight times in four weeks.

During active treatment physiotherapy and occupational therapy were planned according to individual needs. Active physiotherapy was geared to positive treatment using proprioceptive neuromuscular facilitation and Bobath and Peto methods. These were used to improve rotation, balance, and walking, reduce festination, and increase the range of movement where rigidity was a problem. Active occupational therapy was aimed at improving personal independence and furctional activities, such as mobility, feeding, dressing, and cooking. During active therapy relatives were invited to observe treatment and encourage the patient's activities at home. Inactive treatment consisted of infrared radiation to the thorax and diversional activities such as table games and crafts, with minimal supervision.

Of the 24 patients (18 men, average age 68.9 years; six women, average age 73.1 years), eight were withdrawn: one during the initial treatment, four during the three-month gap before cross-over, and three during the second course of treatment. One of these eight patients died, four required treatment for other illnesses, and three could not continue for social reasons. Twenty-three patients completed an initial course, and 16 the full cross-over study.

Results (table) obtained in each test in the assessment made by the doctor before treatment were compared with those obtained immediately after treatment using the sign test for comparison of grades (assessments 1-5) and Wilcoxon's rank paired test for the timed data (assessment 6-9). In no test was there a significant change after treatment.

\section{Comment}

Our results suggest that remedial therapy in a hospital outpatient department is not helpful for patients with Parkinson's disease whose condition is relatively stable and whose medication does not require adjustment. We studied outpatients whose neurological condition

Results of assessments (expressed as mean scores before and after treatment)

\begin{tabular}{|c|c|c|c|c|c|}
\hline & & \multicolumn{2}{|c|}{$\begin{array}{l}\text { Active treatment } \\
\left(\mathbf{n}=21^{*}\right)\end{array}$} & \multicolumn{2}{|c|}{$\begin{array}{l}\text { Inactive treatment } \\
\left(\mathrm{n}=18^{*}\right)\end{array}$} \\
\hline & & Before & After & Before & After \\
\hline $\begin{array}{l}\text { Speech }(0-4) \ldots \\
\text { Gait }(0-4) \\
\text { Posture and balance }(0-4) \\
\text { Rigidity }(0-4) . . \\
\text { Tremor }(0-4) . \\
\text { Time in seconds to stand, } \\
\text { and sit } \\
\text { Number of times opened a } \\
\text { fist (worst hand) in } 10 \text { s } \\
\text { Time in seconds to insert } 6 \\
\text { board } \\
\text { Time in seconds to put } \\
\text { sheet into envelope }\end{array}$ & 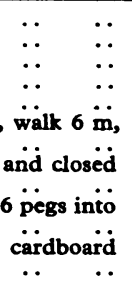 & $\begin{array}{l}1 \cdot 318 \\
1.136 \\
0.956 \\
1.09 \\
0.652 \\
14.95 \\
15.42 \\
12 \cdot 10 \\
23 \cdot 13\end{array}$ & $\begin{array}{l}12.71 \\
12.19 \\
13.45 \\
19.50\end{array}$ & $\begin{array}{c}0.944 \\
1.278 \\
1.000 \\
1.111 \\
0.722 \\
24.37 \\
13222 \\
12.78\end{array}$ & $\begin{array}{l}1.222 \\
1.677 \\
1.222 \\
1.389 \\
0.778 \\
30.92 \\
13.44 \\
13.78\end{array}$ \\
\hline
\end{tabular}

-Figures in parentheses are numbers of patiente-completing treatment. Statistical- No significant difference in any asessment before and af had not been altering appreciably from one outpatient visit to the next; but physiotherapy and occupational therapy might help those who are rapidly deteriorating and in whom several factors might be leading to increasing disability.

Instead of concentrating resources on outpatient remedial therapy, doctors, therapists, and social workers should be providing help within the home to patients with Parkinson's disease and their relatives. Only if remedial therapy is proved useful should it be provided as a routine outpatient service.

We thank Mr D Timlin for help with the statistical analysis, and the Parkinson's Disease Society of the United Kingdom for financial help to provide transport for patients.

(Accepted 26 fanuary 1981)

Queen Mary's Hospital, Roehampton, London SW15 5PN

F B GIBBERD, MD, FRCP, consultant neurologist

N G R PAGE, MB, MRCP, medical registrar (now registrar, St Thomas's Hospital, London EC1)

K M SPENCER, MB, MRCP, medical registrar (now research fellow and honorary senior registrar, St Bartholomew's Hospital, London EC1) E KINNEAR, MCsP, physiotherapist

J B HAWKSWORTH, MBACT, occupational therapist

\section{Raised serum haemolytic complement activity in glomerulonephritis: a bad prognostic sign}

Depression of total serum haemolytic complement $\left(\mathrm{CH}_{30}\right)$ activity or concentration of the third component (C3), or both, is a feature of acute glomerulonephritis, mesangiocapillary glomerulonephritis, and systemic lupus erythematosus. Most patients with other forms of glomerulonephritis have normal serum complement values, but in a minority these may be raised. Excess serum complement has aroused little comment, but in 1972 Gabriel et al noted more rapid deterioration in renal function in patients with raised $\mathrm{CH}_{50}$ activity. No prospective study has been reported to confirm or refute their finding.

\section{Patients, methods, and results}

Serum complement was studied in 110 patients with various forms of glomerulonephritis. $\mathrm{CH}_{50}$ activity was measured by a kinetic method, ${ }^{2}$ and $\mathrm{C} 3$ and $\mathrm{C} 4$ concentrations by single radial immunodiffusion ${ }^{3}$ with Behringwerke Partigen plates. Thirteen patients had $\mathrm{CH}_{50}$ activity more than 2 standard deviations (SD) above the normal mean. A further seven were picked at random from those with high normal levels (1-2 SD above the mean). These 20 patients were matched with a control group of 20 subjects chosen from the 60 patients with $\mathrm{CH}_{50}$ activity \pm 1 SD from the normal mean. They were selected, firstly, to match perfectly for histological diagnosis and sex, then to match as closely as possible for age, duration of the disease, degree of proteinuria, and excretory function (creatinine clearance). As a result the two groups at the start were perfectly matched for histological diagnosis and sex; well matched for mean age ( $37 v 36$ years), duration of disease, $(6.5070$ years), proteinuria $(3602.8 \mathrm{~g} / 24 \mathrm{~h})$, creatinine clearance $(97 v 1091 / 24 \mathrm{~h})$, and hypertension (6/20 v 5/20); but the plasma creatinine concentration was significantly higher in the "high-complement" group than in the controls $(144 v 110 \mu \mathrm{mol} / 1(1.6 v 1.2 \mathrm{mg} / 100 \mathrm{ml}) ; \mathrm{p}<0.01)$.

The figure showe theprogress of renal fanction, as judged by plasma creati$\therefore$ ine concentration 10 of the 20 perimens th raised $\mathrm{CH}_{80}$ ectivity plesma creatinine contration rose, in six cases to over $500 \mu \mathrm{mol} / 1$ (5.7 - $100 \mathrm{ml}$ ). Three cintesect six showed rapitt tererioration of rensl function during the first 18 months. Of the controls, only one showed mild deterioration of renal function. The difference between the two groups in numbers of patients showing deterioration $(10 / 20,1 / 20)$ was significant $\left(\chi^{2}\right.$ test: $\mathbf{p}<0.01$ ).

CE ectivity in the controls remained within the normal range throughout

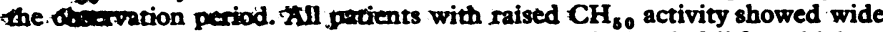
flucrurions during follow-ap, but in only two did the levels fall from high to 


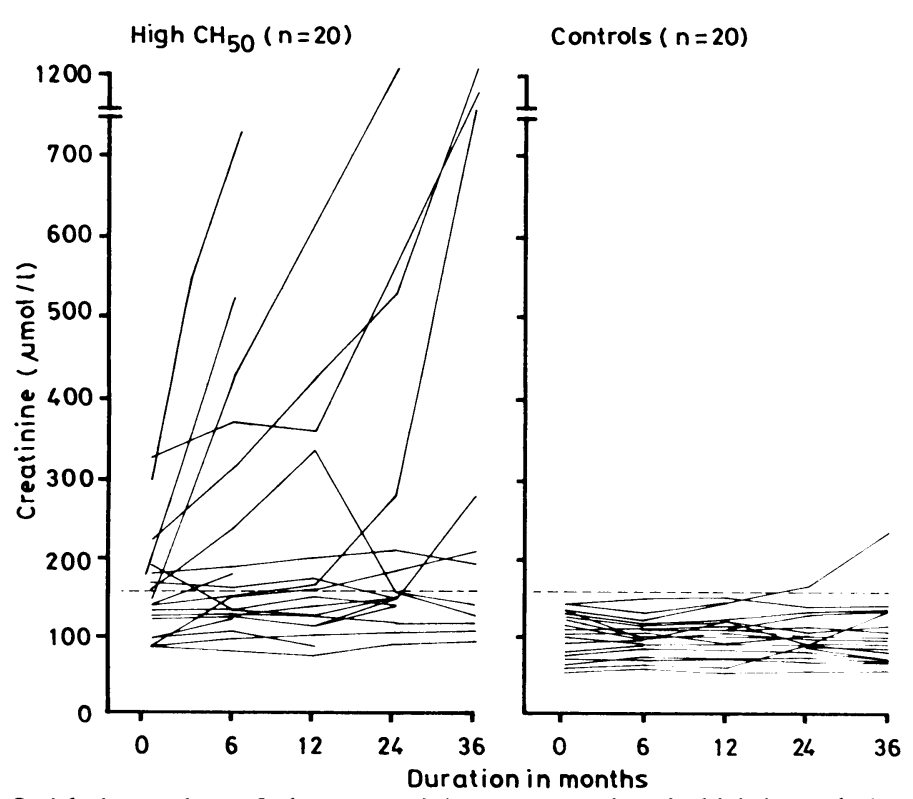

Serial observations of plasma creatinine concentrations in high haemolytic complement $\left(\mathrm{CH}_{50}\right)$ and control groups during three years of prospective study.

Conversion: SI to traditional units-Creatinine: $1 \mu \mathrm{mol} / 1 \approx 0.01 \mathrm{mg} / 100 \mathrm{ml}$.

normal during this period. There was a progressive upward trend in $\mathrm{CH}_{50}$ activity with rise in plasma creatinine concentration, which did not quite achieve significance. This suggested that $\mathrm{CH}_{50}$ activity increases with declining renal function. To test this we studied $\mathrm{CH}_{50}$ activity and $\mathrm{C} 3$ and $\mathrm{C} 4$ concentrations in 20 patients with renal failure due to polycystic kidneys or essential hypertension, all with plasma creatinine concentrations above 600 $\mu \mathrm{mol} / 1(6.8 \mathrm{mg} / 100 \mathrm{ml}) . \mathrm{CH}_{50}$ activity was within normal limits in all, showing that renal failure alone does not affect $\mathrm{CH}_{50} . \mathrm{C} 3$ and $\mathrm{C} 4$ concentrations were also normal in all.

The fluctuations in $\mathrm{CH}_{50}$ activity in this group with active nephritis are unexplained. We measured $\mathrm{CH}_{50}, \mathrm{C} 3$, and $\mathrm{C4}$ values in 10 healthy volunteers daily for five days and monthly for a year. The fluctuations were much smaller than those in our hypercomplementaemic patients, and all remained within the normal range. The wide fluctuations in our high-complement group were therefore an aberration.

Concentrations of $\mathrm{C} 3$ and $\mathrm{C} 4$ did not differ between our two groups of patients or between the patients and controls. They did not exhibit the same fluctuations as $\mathrm{CH}_{50}$. We found no correlation between raised $\mathrm{CH}_{50}$ activity and histological diagnosis, except that no patient with minimal change had raised $\mathrm{CH}_{50}$ activity.

\section{Comment}

This study confirms the observation of Gabriel et al that raised $\mathrm{CH}_{50}$ activity is a bad prognostic marker in glomerulonephritis. It probably reflects activity of the disease in some forms of glomerulonephritis and may indicate overproduction of the complement fractions in response to increased catabolism. If this is the case, however, the third and fourth components do not appear to be the ones responsible for the increased total haemolytic complement.

${ }^{1}$ Gabriel R, Glynn AA, Joekes AM. Raised complement in nephritis: prognostic significance. Lancet 1972;ii:55-7.

${ }^{2}$ Fischer H. Automatic registration of complement and some applications. Symposia Series. Immunobiological Standards 1967;4:221-8.

${ }^{3}$ Mancini G, Carbonara AO, Heremans JF. Immuno-chemical quantitation of antigens by single radial immunodiffusion. Immunochemistry $1965 ; 2$ : 235-54.

(Accepted 16 fanuary 1981)

University of Newcastle upon Tyne, Royal Victoria Infirmary, Newcastle upon Tyne NE1 4LP

H RASHID, MB, FCPS, Commonwealth research fellow

P A E BIRD, PHD, demonstrator in microbiology (now research associate, department of immunology, University of Birmingham)

$T$ VERNAZZA, PHD, demonstrator in microbiology

M SUSSMAN, PHD, FIBIOL, professor of microbiology

A R MORLEY, MD, MRCPATH, consultant pathologist

D N S KERR, MSC, FRCP, professor of medicine

\section{Lecithin treatment in Friedreich's ataxia}

The biochemical basis of Friedreich's ataxia is unknown, though associated defects in the pyruvate dehydrogenase enzyme complex suggest that impaired cholinergic mechanisms may contribute to the neurological deficit. ${ }^{1}$ This raises the therapeutic possibility of supplementing the diet with precursors of acetylcholine. Encouraging results from trials with lecithin and choline chloride have been reported. ${ }^{23} \mathrm{We}$ report a double-blind cross-over trial of lecithin in 12 patients with Friedreich's ataxia.

\section{Patients, methods, and results}

Twelve patients attending neurology clinics in Edinburgh with an established diagnosis of Friedreich's ataxia agreed to participate. Their mean age was 18.8 years (range 11-30 years) and mean duration of illness 7.7 years (range 6 months to 20 years).

Patients were assessed before treatment and at fortnightly intervals thereafter by a battery of clinical tests for dysarthria and ataxia. This included timed handwriting, spiral drawing, and measurement of rapid repetitive finger movements using a simple laboratory cell counter. Each patient was scored for each test on a scale from 0 (normal) to 6 (unable to perform test). Speech was also assessed independently by a speech therapist at monthly intervals. Patients kept daily records of their progress and any side effects.

To disguise the taste and oily nature of lecithin it was incorporated into chocolate bars. Each "active" chocolate bar contained $25 \mathrm{~g}$ of $96 \%$ pure lecithin (Phospholipon 100, Nattermann) in $100 \mathrm{~g}$ chocolate and $40 \mathrm{~g}$ porridge oats. Cocoa butter was substituted for lecithin in the placebo bars. The pharmacist randomly allocated patients to lecithin or placebo treatment initially, and a double-blind cross-over procedure was observed over three months. The patient therefore took a chocolate bar daily for the first and third four-week periods, receiving no treatment during the intervening month.

The table shows the mean numerical ataxia scores for grouped arm functions and the total scores. Individual responses varied but no patient showed any consistent substantial change with treatment. Statistical analysis by the Wilcoxon matched pairs signed ranks test failed to show a significant difference between lecithin and placebo $(p>0.05)$. The speech studies similarly showed no significant change. The patients' subjective impressions were of some improvement with lecithin in four cases, with placebo in three, and no change in five. Six patients complained of anorexia and nausea and one noted excessive salivation and motor restlessness while receiving the active preparation.

Mean ataxia scores

\begin{tabular}{ccccccc}
\hline & & \multicolumn{2}{c}{ Grouped arm functions } & & \multicolumn{2}{c}{ Total score } \\
\cline { 6 - 7 } Case No & Age (years) & $\begin{array}{c}\text { Active } \\
\text { treatment }\end{array}$ & Placebo & & $\begin{array}{c}\text { Active } \\
\text { treatment }\end{array}$ & Placebo \\
\hline 1 & 15 & 16 & 9 & & 46 & 45 \\
2 & 25 & 36 & 40 & & 112 & 116 \\
3 & 30 & 23 & 20 & & 79 & 76 \\
4 & 21 & 15 & 17 & & 39 & 41 \\
5 & 17 & 11 & 16 & & 65 & 42 \\
6 & 27 & 17 & 22 & & 46 & 74 \\
7 & 19 & 15 & 17 & & 24 & 33 \\
8 & 20 & 9 & 14 & & 9 & 4 \\
9 & 13 & 7 & 3 & & 48 & 49 \\
10 & 10 & 22 & 22 & & 43 & 44 \\
11 & 14 & 33 & 34 & & 58 & 54 \\
12 & 12 & 30 & 29 & &
\end{tabular}

\section{Comment}

The results of this study fail to show any beneficial response to lecithin in 12 patients with Friedreich's ataxia. Barbeau described a $35 \%$ mean improvement in 10 patients treated openly with lecithin granules for a mean of 23.9 weeks, with significant improvement after two weeks and maximum response at four weeks, ${ }^{2}$ and other workers reported some improvement with choline chloride. ${ }^{3}$ A more recent study, however, suggested that performance may actually decline in patients with Friedreich's ataxia treated with lecithin, ${ }^{4}$ and animal studies have cast doubt on the idea that increased serum choline concentrations alter the functional activity of acetylcholine at central receptor sites. ${ }^{5}$

Because of the previous reports of early substantial improvement with lecithin ${ }^{2}$ and the difficulty of patients in tolerating the large amounts of chocolate necessary for the double-blind study we did not feel justified in embarking on a more prolonged trial. Unless lecithin can be shown to be an effective cholinergic agent there seems no 